\title{
Thrombolysis in acute ischaemic stroke
}

\author{
A C Pereira, P J Martin, E A Warburton
}

The primary deficit in acute ischaemic stroke is one of impaired blood flow. Part of the cerebral circulation is occluded either by in situ thrombosis, or embolism from the heart or a more proximal artery (for example, the ipsilateral internal carotid artery). Angiographic studies of the cerebral circulation in acute stroke demonstrate occluding thrombus in up to $80 \%$ of patients. ${ }^{1}$ The aim of thrombolytic therapy therefore is to lyse an occluding thrombus or embolus and reduce the volume of cerebral tissue irreversibly damaged. Such an approach is of course successfully employed in the treatment of acute myocardial infarction. ${ }^{2}$ However a major complication of thrombolysis in stroke is cerebral haemorrhage which could offset any beneficial effects. Here we review the available evidence for thrombolysis in acute stroke and suggest imaging methods that could be used to aid future selection of patients who are most likely to benefit from such treatment.

\section{Experimental rationale for thrombolysis in stroke}

Data from animal stroke models confirm that cerebral blood flow can be restored to near normal levels after administration of recombinant tissue plasminogen activator $(\mathrm{rtPA})^{3}$ and that thrombolysis results in smaller infarcts and improved neurological function. ${ }^{4-6}$ Comparison of streptokinase with rtPA suggested that, although their effectiveness in producing thrombolysis was comparable, streptokinase was less clot specific and animals treated with it had increased frequency and severity of cerebral haemorrhage. ${ }^{7}$ Animals treated with rtPA had the same frequency of cerebral haemorrhages as those treated with saline but the proportion of large haematomas was increased. ${ }^{6}$

In humans, thrombolytic therapy was first tried over 40 years ago but was largely abandoned due to excess mortality from major haemorrhagic complications. ${ }^{8}$ When computed tomography became widely available interest in the use of thrombolysis returned, leading to several larger randomised controlled trials. A dose escalation study using rtPA reported that the proportion of patients in whom recanalisation was demonstrated was independent of the dose of rtPA used. ${ }^{1}$ The overall recanalisation rate immediately after rtPA infusion for extracranial internal carotid artery occlusions was $8 \%$ and for major coronary artery occlusions was $26 \%-38 \%$. Patients who had a cerebral haemorrhage received rtPA significantly later than those who had no haemorrhage (6.1(1.5) compared with $5.3(1.7)$ hours, $\mathrm{p}=0.006)$. This suggested that six hours might be the latest time after the onset of stroke where it was safe to use rtPA. Animal experiments also showed that increasing the duration of ischaemia up to three hours yielded progressively larger infarcts but, beyond three hours, final infarct size was independent of the duration of ischaemia. This suggested that three hours was the time window for intervention before cells became irreversibly damaged. ${ }^{9}$ As the primary pathology in ischaemic stroke is severe reduction of blood flow, it seemed logical to try to reverse this as soon as possible. Therefore, a further dose escalation study of urgent thrombolysis within 90 minutes from onset of stroke using rtPA was started. ${ }^{10} \mathrm{~A}$ dose related effect on intracranial haemorrhage was noted: no patient treated with $0.95 \mathrm{mg} / \mathrm{kg} \mathrm{rtPA}$ suffered an intracranial haemorrhage but $3 / 26$ patients treated with higher doses did suggesting that doses up to $0.9 \mathrm{mg} / \mathrm{kg}$ may be safely administered to acute stroke patients. Further studies suggested that the time window for treatment could be safely extended to three hours. ${ }^{11}$ In summary this evidence suggested that rtPA was an appropriate thrombolytic agent when administered at a dose of $0.9 \mathrm{mg} / \mathrm{kg}$ to patients within three hours of the onset of acute stroke. It is of interest that the only trial that has shown a benefit of thrombolysis is also the only trial to have adhered to these criteria. ${ }^{12}$

\section{Recent randomised controlled trials}

In stroke patients seven major randomised trials of urgent thrombolytic therapy have been published. Three used streptokinase as the thrombolytic agent: the Australian Streptokinase Trial (ASK), ${ }^{13}$ the Multi-centre Acute Stroke Trial-Italy (MAST-I), ${ }^{14}$ and the Multicentre Acute Stroke Trial-Europe (MAST-E). ${ }^{15}$ Four used rtPA as the thrombolytic agent: the National Institute of Neurological Disorders and Stroke (NINDS) ${ }^{12}$ trial, the first and second European Co-operative Acute Stroke Studies (ECASS $1^{16}$ and ECASS $2^{17}$ ), and the Alteplase Thrombolysis for Acute Noninterventional Therapy in Ischaemic Stroke (ATLANTIS) Study ${ }^{18}$. The most important data in studies such as these are the safety of the treatment (indicated by the early death or haemorrhage rate) and the efficacy (death or dependency at the end of trial follow up). Table 1 shows these figures for each trial.

\section{STREPTOKINASE TRIALS}

The three streptokinase trials were all stopped early because of concerns over safety. The ASK trial randomised patients to either streptokinase or placebo administered within four hours from symptom onset; 340 patients were enrolled in the trial. However, there was a significant increase in mortality in patients given streptokinase compared with placebo, particularly after three hours $(43.4 \%$ v $22.1 \%$, $\mathrm{p}<0.001) .{ }^{19}$ Interestingly, there was no such increase in hazard in patients treated within
Submitted 18 February 2000 Accepted 4 July 2000 
Table 1 Randomised controlled trials and meta-analysis of thrombolysis in acute stroke showing rates of early death up to 30 days, dependency (usually defined as a Rankin score greater than 2 (inclusive) or death at up to 6 months and rates of symptomatic intracranial haemorrhage)

\begin{tabular}{|c|c|c|c|c|}
\hline Trial & No & Drug/time & Thrombolytic (\%) & Control (\%) \\
\hline $\mathrm{ASK}^{13}$ & 340 & SK & & \\
\hline Early death $(7 \text { days })^{\star}$ & & $<4$ hours & 17.8 & 10.9 \\
\hline Death/dependency ( 3 months) & & & 42.3 & 44.6 \\
\hline Haemorrhage* & & & 12.6 & 2.4 \\
\hline MAST-E ${ }^{15}$ & 310 & SK & & \\
\hline Early death $(10 \text { days })^{\star}$ & & $<6$ hours & 34.0 & 18.2 \\
\hline Death/dependency (6 months) & & & 79.5 & 81.8 \\
\hline${\text { Haemorrhage }{ }^{\star}}^{-1}$ & & & 21.2 & 2.6 \\
\hline MAST-I $^{14}$ & 622 & SK & & \\
\hline Early death $(10 \text { days })^{\star}$ & & $<6$ hours & 26.5 & 11.7 \\
\hline Death/dependency ( 6 months) & & & 62.6 & 64.7 \\
\hline Haemorrhage ${ }^{\star}$ & & & 8.0 & 1.3 \\
\hline ECASS $1^{16}$ & 620 & $\mathrm{rtPA}$ & & \\
\hline Early death (30 days) ${ }^{\star}$ & & $<6$ hours & 17.9 & 12.7 \\
\hline Death/dependency ( 3 months) & & & 63.3 & 71.7 \\
\hline Haemorrhage ${ }^{\star}$ & & & 19.8 & 6.5 \\
\hline NINDS $^{12}$ & 624 & rtPA & & \\
\hline Early death (30 days) & & $<3$ hours & 12.8 & 15.7 \\
\hline Death/dependency (3 months) & & & 57.4 & 73.4 \\
\hline${\text { Haemorrhage }{ }^{\star}}^{-1}$ & & & 6.4 & 0.6 \\
\hline \multicolumn{5}{|l|}{ Meta-analysis ${ }^{22}$} \\
\hline Early death $\star$ & 3435 & $\mathrm{SK} / \mathrm{rtPA}$ & 20.9 & 11.8 \\
\hline Death/dependency ${ }^{\star}$ & & & 61.5 & 68 \\
\hline Haemorrhage $^{\star}$ & & & 9.6 & 2.6 \\
\hline ECASS $2^{17}$ & 800 & $\mathrm{rtPA}$ & & \\
\hline Early death (7 days) & & $<6$ hours & 6.1 & 4.9 \\
\hline Death/dependency ( 3 months) & & & 59.7 & 63.4 \\
\hline Haemorrhage^ & & & 8.8 & 3.4 \\
\hline ATLANTIS $^{18}$ & 613 & $\mathrm{rtPA}$ & & \\
\hline Early death (30 days) & & $3-5$ hours & 7.6 & 4.2 \\
\hline Death/dependency ( 3 months) & & & 58.3 & 59.5 \\
\hline Haemorrhage ${ }^{\star}$ & & & 6.7 & 1.3 \\
\hline
\end{tabular}

The asterisks $\left(^{\star}\right)$ signify that the difference between the two groups reached statistical significance No is the number of subjects in each study; SK is streptokinase and rtPA is recombinant tissue plasminogen activator. sustained to one year. ${ }^{21}$ Furthermore, although there was a significant increase in the frequency of symptomatic intracerebral haemorrhage, this did not produce an increase in the early death rate. The frequency of asymptomatic haemorrhage was similar in both groups $(4 \%$ treated with rtPA and 3\% in controls). The frequency of serious extracranial haemorrhage was about $1 \%$.

The European trial comparable to the NINDS study was ECASS 1 . This randomised 620 patients to receive either $1.1 \mathrm{mg} / \mathrm{kg}$ of $\mathrm{rtPA}$ or placebo within six hours of the onset of stroke. A target population of patients was defined with moderate to severe stroke with only minor signs of ischaemia on the randomisation computed tomogram. The intention to treat analysis demonstrated a significant increase in early mortality and haemorrhage and a non-significant improvement in final outcome. However, retrospective analysis of the randomisation data highlighted 109 patients who had a protocol violation, usually more extensive changes on randomisation computed tomography than desired. These patients' data were removed post hoc and analysis of the target population was repeated. This suggested that, had only members of the target population been randomised, there would have not been an increase in early mortality and their final outcome would have significantly improved. This was particularly true for those patients in the target group randomised within three hours. $^{22}$ However, this post hoc procedure clearly was biased: $21 \%$ of rtPA treated patients were removed (of whom $30 \%$ died) compared with $14 \%$ of controls (of whom $19 \%$ died). In ECASS 2, therefore, centres underwent training to standardise the interpretation of early computed tomograms. Furthermore, the lower dose of rtPA (as used in the NINDS study) was administered. ECASS 2 demonstrated a significant increase in symptomatic intracerebral haemorrhage but without a significant increase in early mortality; there was no significant improvement in final outcome. This result was disappointing. However, the strict inclusion criteria may have yielded a population of stroke patients with less severe strokes. Compared with the control groups of the NINDS study and ECASS 1, of whom $73.4 \%$ and $71.7 \%$ respectively had poor final outcomes, the figure in ECASS 2 was $63.4 \%$.

The ATLANTIS study provided data on thrombolysis from three to five hours after the onset of stroke. Some caution is needed when interpreting the results as two changes in trial protocol were made during recruitment of patients. The initial study in 1991 was a comparison of $\mathrm{rtPA}(0.9 \mathrm{mg} / \mathrm{kg})$ against placebo for acute stroke patients within six hours of the onset of symptoms. However, in 1993, safety concerns regarding patients randomised after five hours resulted in the trial being halted. Recruitment later restarted (as ATLANTIS B) using a new zero to five hours time window. In 1996, after publication of the NINDS trial, the time window was further modified to three to five hours. Data from these "target group" patients have been published that patients treated with thrombolysis were at least $30 \%$ more likely to have minimal or no disability at three months and this benefit was 
recently. ${ }^{18}$ The results do not show any benefit for the thrombolysis over placebo for patients randomised between three and five hours after stroke.

Overall, therefore, the trials suggest that streptokinase is more hazardous to the cerebral circulation than rtPA. None of the streptokinase trials reached completion. The major differences between the NINDS study and ECASS 1 were the dose of rtPA used and the time interval from stroke onset and treatment. When the issue of dose was addressed in ECASS 2, a positive treatment benefit was still not confirmed but there was no increase in early mortality. These data suggest that rtPA given within six hours of stroke onset may be safe but may not be effective after three hours. A meta-analysis of the data from all the thrombolysis trials except ECASS 2 (3435 patients) confirmed the early hazard from thrombolysis (mainly from streptokinase) but suggested there may be a significant overall benefit of $6.5 \%{ }^{22}$ A more recent overview from the Cochrane database which added data from patients in ECASS 2 and ATLANTIS confirmed the findings of the first meta-analysis. ${ }^{23}$ In 4236 patients, thrombolysis increased the risk of symptomatic intracranial bleeding from $2.5 \%$ to $9.4 \%$ but against this was the benefit that a significantly smaller proportion of patients (55.2\% compared with $59.7 \%$ ) were dead or dependent at three to six months. This means that for every 1000 patients treated, 65 extra patients would be independent by three to six months. This means that for every 1000 patients treated, 44 extra patients would be independent by three to six months. Both these meta-analyses may be criticised for combining the results from both, streptokinase and rtPA, trials.

On the basis of the NINDS trial, the US Food and Drug Administration licensed rtPA for treatment of acute stroke patients within three hours of onset of their symptoms. Although a recent series from centres in the USA suggested that favourable clinical outcomes and low rates of symptomatic intracerebral haemorrhage could be achieved using $\mathrm{rtPA},{ }^{24}$ the other negative trials have tempered enthusiasm for the use of thrombolysis in routine practice in Europe and means that a further trial will be necessary before this treatment is widely accepted as beneficial. ${ }^{25}$ Furthermore, a recent survey of 3948 stroke patients admitted to 29 hospitals in Cleveland, Ohio, showed that $10.4 \%$ were admitted within three hours and $1.8 \%$ were given rtPA. Half of these patients deviated from the national treatment guidelines. ${ }^{26}$ The incidence of symptomatic intracerebral haemorrhage was $15.7 \%$, much higher than in comparable trials, thus highlighting the need to know the risks and benefits of thrombolysis in a more general and representative clinical setting.

Problems in the design and interpretation of human trials

Part of the problem in judging the utility of thrombolysis is that often the underlying pathology is not taken into consideration.
Clearly an important principle of rational treatment is to ensure that the patient has the target problem: there seems little point treating patients with thrombolysis if the occlusion has already dissipated. ${ }^{27}$ Other considerations such as whether thrombolysis was successful in individual patients (that is, broke down the occluding clot) and identification of patients at most risk of haemorrhage have been poorly addressed.

Ischaemic stroke is a heterogeneous clinical condition. Patients presenting with lacunar syndromes or large vessel occlusion syndromes have different prognoses ${ }^{28}$ and these need to be considered when interpreting the results of treatment trials. In the NINDS trial, $16 \%$ of patients given rtPA had lacunar infarcts while $38 \%$ had large vessel occlusions compared with $10 \%$ and $43 \%$ respectively in the control group. Therefore, it is possible that some of the apparent benefit attributed to thrombolysis may reflect the different mix of pathology in the two groups. Future stroke trials should take these pathological subtypes of stroke into account during randomisation.

There is no routine practice to ensure that thrombolysis has successfully produced recanalisation. Reperfusion is less likely to be achieved with proximal internal artery occlusions rather than more distal middle cerebral artery occlusion. ${ }^{1}$ Reperfusion rates after intravenous thrombolysis are reported to be $30 \%$ immediately after infusion, ${ }^{129} 53 \% \quad 12-24$ hours later, ${ }^{29}$ and $65 \%$ within three days. ${ }^{30}$ Reperfusion is associated with smaller infarcts and better clinical outcome. ${ }^{29}{ }^{30}$ Intra-arterial thrombolysis produces a higher rate of recanalisation $(58 \%)$ immediately after the infusion but has not been shown to improve clinical outcome. $^{31}$ Therefore, in future, it may be important to include a measure of perfusion to ascertain whether recanalisation has occurred and to aid decisions regarding further thrombolysis.

The major adverse effect of thrombolysis is intracranial haemorrhage. Haemorrhage is a common sequelae of stroke and the spontaneous haemorrhage rate in stroke patients is high. In ECASS 2, the frequency of all haemorrhage was similar in the rtPA and control groups ( $48.4 \%$ v $40.2 \%$ respectively), but, in the rtPA group, there was a significant increase in parenchymal haemorrhage $(11.8 \% \quad v \quad 3.1 \%)$ and large haematomas $(8.1 \% v 0.8 \%)$. The larger parenchymal haemorrhages were more likely to cause neurological worsening. ${ }^{32}$ Therefore, rtPA seems to increase the severity of haemorrhage rather than the incidence of haemorrhage. Haemorrhage is more likely to occur late after the onset of stroke when cell necrosis causes blood vessels to break down. ${ }^{33}$ In the NINDS trial, haemorrhage was more likely in patients with a more severe neurological deficit at randomisation, a mass effect, or cerebral oedema on randomisation computed tomography. ${ }^{34}$ There does seem to be evidence to suggest that if an infarct is visible on the initial computed tomography that the infarction process is advanced and that the risk of haemorrhage is higher than for patients with normal 


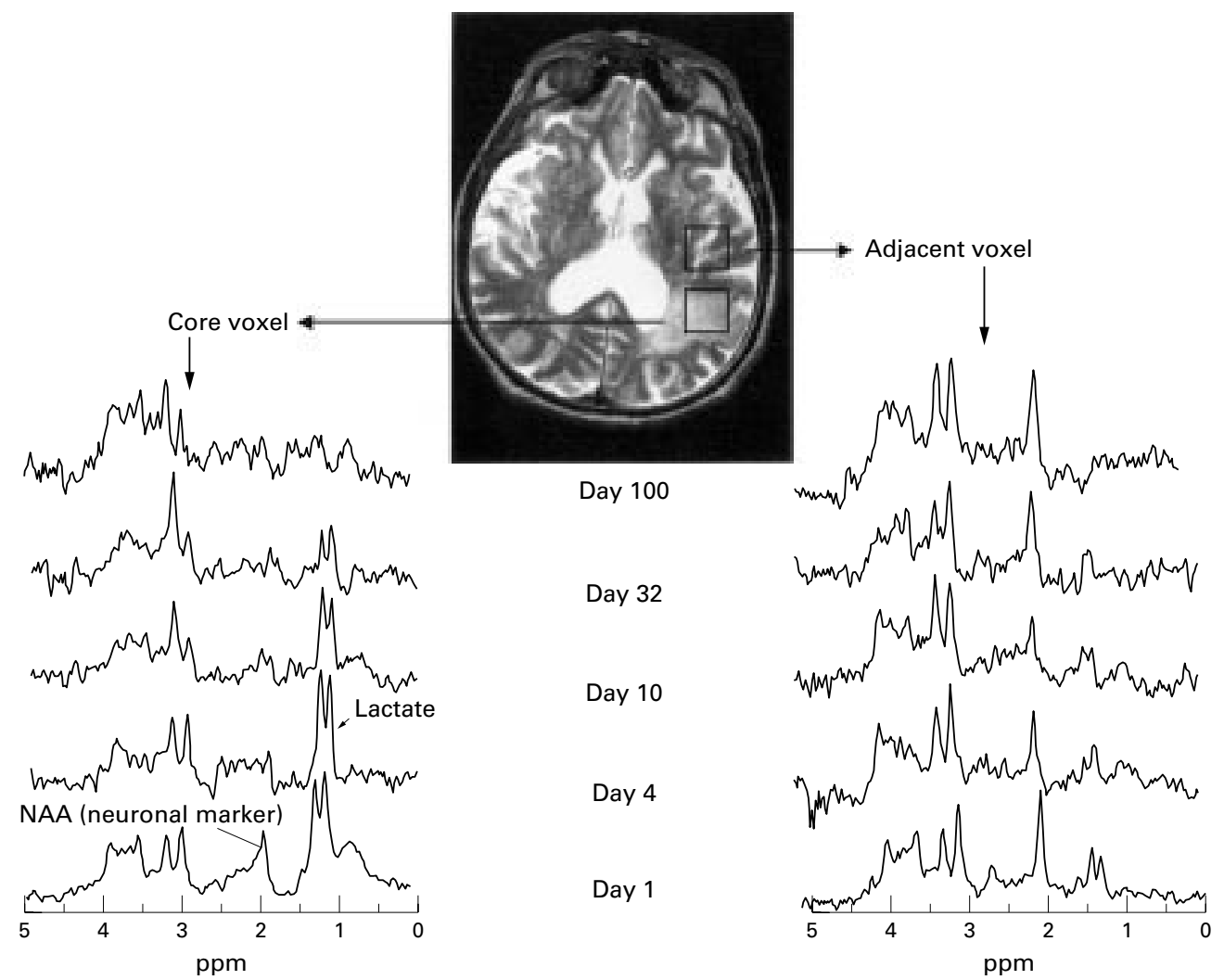

Figure $1 T_{2}$-weighted image showing the central slice of an acute left hemisphere middle cerebral artery infarct. Two voxels are identified: a "core" voxel and an "adjacent" voxel. Each voxel was studied on five occasions at the times shown. The ${ }^{1} H$ $M R$ spectra from each voxel are shown and the metabolites, $N$-acetyl aspartate (NAA, a neuronal marker) and lactate (a marker of ischaemia) are labelled. The area under each metabolite peak in the spectrum is proportional to the metabolite concentration. The figure demonstrates that in the core voxel, lactate is present for several weeks and neuronal loss continues until virtually no NAA is detectable. In the voxel adjacent to the visible infarct, even though there is no abnormal

$T_{2}$-weighted signal, lactate is present implying ischaemia of this adjacent tissue. This technique may in future play a part in identifying viable neuronal tissue or ischaemic tissue that may benefit from thrombolysis.

or mildly abnormal computed tomograms. ${ }^{35}$ However, even patients with extensive abnormalities on the initial scan or more severe clinical deficits can benefit from thrombolysis. ${ }^{36-38}$ Therefore, more sophisticated methods of assessing the underlying pathology of cerebral ischaemia are required.

\section{Imaging in acute stroke}

Most trials have used unenhanced computed tomography as the necessary imaging investigation before randomisation. In the early phase of stroke, computed tomography is very good at demonstrating haemorrhage but up to $50 \%$ of computed tomograms may be normal and not show the area of infarction. ${ }^{39-41}$ Furthermore, computed tomography provides no information about perfusion or about cellular function. Therefore, it has major disadvantages in the early stage of stroke. Single photon emission tomography (SPECT) or xenon computed tomography can address some of these deficiencies and provide a measure of perfusion..$^{42}{ }^{43}$ A more informative technique is positron emission tomography (PET) which provides measures of perfusion and cellular metabolism. ${ }^{44}$ In fact, PET has demonstrated that substantial ischaemic regions survive for up to a month after the onset of stroke in humans, suggesting that there was hope of cell recovery for quite a prolonged period of time. ${ }^{45} 46$ This has very important treatment implications as it suggests that some patients may still benefit from therapy at extended time periods. ${ }^{46}$ As it is unlikely that many stroke patients will undergo a PET scan, a more widely available and useful investigation is the use of magnetic resonance imaging. Magnetic resonance angiography can show the occluded artery. ${ }^{47}$ Diffusion weighted imaging (DWI) demonstrates the region of infarction within minutes of the onset of stroke, ${ }^{48}$ while perfusion imaging can demonstrate a region of low cerebral blood flow. ${ }^{40}$ Magnetic resonance spectroscopy ( ${ }^{1} \mathrm{H}$ MRS) demonstrates biochemical changes occurring in the region of infarction ${ }^{51}$ and may be used to identify surviving neuronal tissue in a region of ischaemia that may be salvageable using thrombolysis (fig 1). ${ }^{52}$ The size of the defect visible on DWI correlates with the size of the infarct pathologically ${ }^{53}$ and the volume of the infarct measured early using DWI,${ }^{54} \mathrm{~T}_{2}$-weighted images, ${ }^{55}$ perfusion imaging, ${ }^{56}$ or combination with ${ }^{1} \mathrm{H}$ MRS ${ }^{57}$ correlates with clinical outcome. Infarcts where the perfusion deficit is larger than the DWI lesion are likely to increase in size suggesting that regions having decreased perfusion without DWI changes may be most suitable for thrombolysis. ${ }^{58}{ }^{59}$ These new techniques may improve the acute assessment of stroke patients and allow individual patients to be assessed and given thrombolysis at more prolonged time intervals after the onset of stroke. ${ }^{46} 60$ 


\section{Summary}

In conclusion, thrombolysis with rtPA given within six hours of the onset of stroke in carefully selected patients is a safe therapy. However, efficacy has only been demonstrated within three hours after stroke onset. At present, only $6 \%{ }^{61}-12 \%{ }^{62}$ of all stroke patients are likely to be eligible for thrombolysis. Improved methods for investigating acute stroke, particularly magnetic resonance techniques, may improve the appropriate targeting of this treatment to those patients most likely to benefit. What is certain is that any increasing use of thrombolysis will have major effects on stroke services. The emphasis will have to be on early assessment and referral, if only to reach an imaging facility for a treatment decision to be made.

EAW is supported by a PPP mid-career fellowship.

1 del Zoppo GJ, Poeck K, Pessin MS, et al. Recombinant tissue plasminogen activator in acute thrombotic and embolic stroke. Ann Neurol 1992;32:78-86.

2 ISIS-2 Collaborative Group. Randomised trial of intravenous streptokinase, oral aspirin, both or neither among 17187 of acute myocardial infarction. Lancet 1988;ii:34960.

3 Papadopoulos SM, Chandler WF, Salamat MS, et al. Recombinant human tissue-type plasminogen activator therapy in acute thromboembolic stroke. $\mathcal{F}$ Neurosurg 1987; 67:394-8.

4 del Zoppo GJ, Copeland BR, Waltz TA, et al. The beneficial effect of intracarotid urokinase on acute stroke in the effect of intracarotid urokinase on a

5 Zivin JA, Lyden PD, DeGirolami U, et al. Tissue plasminoZivin JA, Lyden PD, DeGirolami U, et al. Tissue plasminogen activator. Reduction in neurologic damage after

6 Lyden PD, Zivin JA, Clark WM, et al. Tissue plasminogen activator-mediated thrombolysis of cerebral emboli and its effect on haemorrhagic infarction in rabbits. Neurology 989;39:703-8.

7 Lyden PD, Madden KP, Clark WM, et al. Incidence of cerbral haemorrhage after antifibrinolytic treatment for embolic stroke in rabbits. Stroke 1990;21:1589-93.

8 Sussman BJ, Fitch TSP. Thrombolysis with fibrinolysin in cerebral arterial occlusion. $7 A M A$ 1958;167:1705-9.

9 Memezawa H, Smith M-L, Siesjo BK. Penumbral tissues salvaged by reperfusion following middle cerebral artery occlusion in rats. Stroke 1992;23:552-9.

10 Brott TG, Haley ECJ, Levy DE, et al. Urgent therapy for stroke. Part I. Pilot study of tissue plasminogen activator administered within 90 minutes. Stroke 1992;23:632-40.

11 Haley ECJ, Levy DE, Brott TG, et al. Urgent therapy for stroke. Part II. Pilot study of tissue plasminogen activator
administered 91-180 minutes from onset. Stroke 1992;23: 641-5.

12 National Institute of Neurological Disorders and Stroke rt-PA Stroke Study Group. Tissue plasminogen activator for acute ischemic stroke. N Engl F Med 1995;333:1581-7.

3 Donnan GA, Davis SM, Chambers BR, et al and for the Australian Streptokinase (ASK) Trial Study Group. Streptokinase for acute ischaemic stroke with relationship to time of administration. FAMA 1996;276:966.

14 Multi-centre Acute Stroke Trial-Italy (MAST-I) Group. Randomised controlled trial of streptokinase, aspirin and combination of both in treatment of acute ischaemic stroke. Lancet 1995;346:1509-14.

15 Multicenter Acute Stroke Trial-Europe Study Group. Thrombolytic therapy with streptokinase in acute ischemic stroke. N Engl f Med 1996;335:145-50.

16 Hacke W, Kaste M, Fieschi C, et al, and for the ECASS Study Group. Intravenous thrombolysis with recombinan Study Group. Intravenous thrombolysis with recombinant
tissue plasminogen activator for acute hemispheric stroke. tissue plasminogen activator

17 Hacke W, Kaste M, Fieschi C W, et al. Randomised doubleblind placebo controlled trial of thrombolytic therapy with intravenous alteplase in acute ischaemic stroke (ECASS II). Lancet 1998;352:1245-51.

18 Clark WM, Wissman S, Albers GW, et al and for the ATLANTIS Study Investigators. Recombinant tissue-type plasminogen activator (alteplase) for ischaemic stroke 3 to 5 hours after symptom onset. $\mathcal{F A M A}$ 1999;282:2019-26.

19 Donnan GA, Davis SM, Chambers BR, et al. Trials of streptokinase in severe acute ischaemic stroke. Lancet 1995;345: 578-9.

20 International Stroke Trial Collaborative Group. The International Stroke Trial (IST): a randomised trial of aspirin, subcutaneous heparin, both, or neither among 19435 patients with acute ischaemic stroke. Lancet 1997;349: patients $1569-81$.

21 Kwiatkowski TG, Libman RB, Frankel M, et al. Effects of tissue plasminogen activator for acute ischaemic stroke. $N$ tissue plasminogen activator
Engl f Med 1999;340:1781-7.
22 Wardlaw JM, Warlow CP, Counsell C. Systematic review of evidence on thrombolytic therapy for acute ischaemic evidence on thrombolytic therap
stroke. Lancet 1997;350:607-14.

23 Wardlaw, JM Yamaguchi T, del Zoppo GJ. Thrombolytic therapy versus control in acute ischaemic stroke. Cochrane database of systematic reviews. Stroke Module, 1997.

24 Albers GW, Bates VE, Clark WM, et al. Intravenous tissuetype plasminogen activator for treatment of acute stroke. The standard treatment with alteplase to reverse stroke (STARS) study. $\mathcal{F} A M A$ 2000;283:1145-50.

25 Lindley RI, Waddell F, Livingstone $\mathrm{M}$, et al. Can simple questions assess outcome after stroke? Cerebrovasc Dis 1994; 4:314-24.

26 Katzan IL, Furlan AJ, Lloyd LE, et al. Use of tissue-type plasminigen activa

27 Caplan LR, Mohr JP, Kistler JP, et al. Should thrombolytic therapy be the first-line treatment for acute ischemic stroke? Thrombolysis-not a panacea for ischemic stroke. N Engl f Med 1997;337:1309-10 (see discussion 1313).

28 Bamford JM, Sandercock PAG, Dennis MS, et al. Classification and natural history of clinically identifiable subtypes of cerebral infarction. Lancet 1997;337:1521-6.

29 von Kummer R, Hacke W. Safety and efficacy of intravenous tissue plasminogen activator and heparin in acute middle cerebral artery stroke. Stroke 1992;23:646-52.

30 Ringelstein EB, Biniek R, Weiller C, et al. Type and extent of hemispheric brain infarctions and clinical outcome in early and delayed middle cerebral artery recanalization. Neurology 1992;42:289-98

31 del Zoppo G, Higashida RT, Furlan AJ, et al and the PROACT Investigators. PROACT: a phase II randomised trial of recombinant pro-urokinase by direct arterial delivery in acute middle cerebral artery stroke. Stroke 1998;29:11.

32 Fiorelli M, Bastianello S, von Kummer R, et al. Hemorrhagic transformation within 36 hours of a cerebral infarct. Relationships with early clinical deterioration and 3 month outcome in the European Cooperative Acute Stroke Study (ECASS I) cohort. Stroke 1999;30:2280-4.

33 del Zoppo GJ, von Kummer R, Hamann GF. Ischaemic damage of brain microvessels: inherent risks for thrombolytic treatment in stroke [editorial]. I Neurol Neurosurg Psychiatry 1998;65:1-9.

34 Anonymous. Intracerebral hemorrhage after intravenous t-PA therapy for ischemic stroke. The NINDS t-PA Stroke Study Group. Stroke 1997;28:2109-18.

35 Wardlaw JM, Lewis SC, Dennis MS, et al. Is visible infarction on computed tomography associated with an adverse prognosis in acute ischaemic stroke? Stroke 1998;29:1315progno.

36 Trouillas P, Nighoghossian N, Getenet JC, et al. Open trial of intravenous tissue plasminogen activator in acute carotid territory stroke. Correlations of outcome with clinical and territory stroke. Correlations of outcome

37 Trouillas P, Nighoghossian N, Derex L, et al. Thrombolysis with intravenous rtPA in a series of 100 cases of acute carotid territory stroke: determination of etiological, topographic, and radiological outcome factors. Stroke 1998;29: $2529-40$.

38 Anonymous. Generalized efficacy of t-PA for acute stroke. Subgroup analysis of the NINDS t-PA Stroke Trial. Stroke 1997;28:2119-25.

39 Bryan RN, Levy LM, Whitlow WD, et al. Diagnosis of acute cerebral infarction: comparison of CT and MR imaging. AfNR 1991;12:611-20.

40 Lindgren A, Norrving B, Rudling O, et al. Comparison of clinical and neuroradiological findings in first ever stroke: a population based study. Stroke 1994;25:1371-7.

41 Mohr JP, Biller J, Hilal SK, et al. Magnetic resonance versus computed tomographic imaging in acute stroke. Stroke

42 Lassen NA, Fieschi C, Lenzi G-L. Ischaemic penumbra and neuronal death: comments on the therapeutic window in acute stroke with particular reference to thrombolytic therapy. Cerebrovasc Dis 1991;1:32-5.

43 Wolfson SK, Clark J, Greenberg JH, et al. Xenon-enhanced computed tomography compared with ${ }^{14} \mathrm{C}$ iodoantipyrine for normal and low cerebral blood flow states in baboons. Stroke 1990;21:751-7.

44 Baron JC. Pathophysiology of acute cerebral ischaemia: PET studies in humans. Cerebrovasc Dis 1991;1:22-31.

45 Marchal G, Beaudouin V, Rioux P, et al. Prolonged persistence of substantial volumes of potentially viable brain tissue after stroke: a correlative PET-CT study with voxel-based data analysis [see comments]. Stroke 1996;27:599-606.

46 Baron JC, von Kummer R, del Zoppo GJ. Treatment of acute ischemic stroke. Challenging the concept of a rigid and universal time window [editorial]. Stroke 1995;26: and univers $2219-21$.

47 Prichard JW. Nuclear magnetic resonance methods in stroke. Stroke 1994;24(suppl I);I-70-I71.

8 Moseley ME, Butts K, Yenari MA, et al. Clinical aspects of DWI. NMR in Biomedicine 1995;8:387-96.

49 Fisher M, Prichard JW, Warach S. New magnetic resonance techniques for acute ischemic stroke. $\mathcal{F A M A}$ 1995;274:90811.

50 Baird AE, Warach S. Magnetic resonance imaging of acute stroke. F Cereb Blood Flow Metab 1998;18:583-609.

51 Howe FA, Maxwell RJ, Saunders DE, et al. Proton spectroscopy in vivo. Mag Reson $Q$ 1993;9:31-59.

52 Back T, Hoehn-Berlage M, Kohno K, et al. Diffusion nuclear magnetic resonance imaging in experimental stroke. Correlation with cerebral metabolites. Stroke 1994;25:494500 
53 Warach S, Dashe JF, Edelman RR. Clinical outcome in ischemic stroke predicted by early diffusion-weighted and perfusion magnetic resonance imaging: a preliminary analysis. 7 Cereb Blood Flow Metab 1996;16:53-9.

54 van Everdingen KJ, van der Grond J, Kappelle LJ, et al. Diffusion-weighted magnetic resonance imaging in acute stroke. Stroke 1998;29:1783-90.

55 Saunders DE, Clifton AG, Brown MM. Measurement of infarct size using MRI predicts prognosis in middle cerebral artery infarction. Stroke 1995;26:2272-6.

56 Barber PA, Darby DG, Desmond PM, et al. Prediction of stroke outcome with echoplanar perfusion- and diffusionweighted MRI. Neurology 1998;51:418-26.

57 Pereira AC, Saunders DE, Doyle VL, et al. Measurement of initial $\mathrm{N}$-acetyl aspartate concentration using magnetic resonance spectroscopy and initial infarct volume using MRI predicts outcome in patients with middle cerebral artery territory infarction. Stroke 1999;30:1577-82.
58 Busza AL, Allen KL, King MD, et al. Diffusion-weighted imaging studies of cerebral ischaemia in gerbils. Stroke 1992;23:1602-12.

59 Baird AE, Benfield A, Schlaug G, et al. Enlargement of human cerebral ischaemic lesion volumes measured by diffusion weighted magnetic resonance imaging. Ann Neurol 1997;41:581-9.

60 Albers GW. Expanding the window for thrombolytic therapy in acute stroke. The role of acute MRI for patient selection. Stroke 1999;30:2230-7.

61 Chiu D, Krieger D, Villar-Cordova C, et al. Intravenous tissue plasminogen activator for acute ischemic stroke: feasibility, safety, and efficacy in the first year of clinical practice [see comments]. Stroke 1998;29:18-22.

62 Grond M, Stenzel C, Schmulling S, et al. Early intravenous thrombolysis for acute ischemic stroke in a communitybased approach. Stroke 1998;29:1544-9. 